ing of the school age to sixteen. There is much to be said in favour of both suggestions, and indeed the former is essential; but those who have thought over the problem feel that the raising of the school age will provide no remedy unless what may be called post-elementary or secondary education is directed into channels which will lead up to and adequately prepare children for their future work, whether of a professional, commercial, or industrial character. For professional and commercial occupations ordinary education has done something, but not enough; but for industrial occupations very little has been done except by classes which have been attended by students after a break of two or three years, during which time they have forgotten much that they had learnt at school. The need for some reform in our educational work and for an extension of education in continuation schools has been pointed out in papers read at the British Association meetings, in reports by the British Science Guild and the Consultative Committee of the Board of Education, and at conferences of education authorities.

The resolutions passed and the opinions expressed at the recent conference held at the Guildhall (see NATURE, March 2, p. 3I), supported as they were by men and women representing all classes of the community, may be considered as evidence of a strong feeling that the time has come for some definite action to be taken. As an industrial nation we cannot afford to neglect the adequate preparation of our children for their future careers any longer.

Doubtless the commercial training required for professional or clerical occupations presents the least difficulty, because such training is more or less. intimately connected with an extension of the curricula of higher grade and secondary schools with a definite objective, and generally there is no opposition to such education. The problems connected with the training of those who will take up occupations of a manual or industrial description are more difficult. As soon as such training is talked about there appears to be a general, though erroneous, fear that such training implies definite trade training, and that the market will be flooded with skilled workers; but an inspection of the work and methods of the schools to which we refer later on will show that this is unfounded. The object of these schools is to prepare those boys and girls who intend to enter various trades, so that they will have an opportunity of becoming skilled all-round workers rather than one-branch hands. The changed conditions of manufacture make some system of preparation in schools and technical institutions an absolute necessity.

In any general scheme, local trade conditions will have to be taken into account by local education authorities in arranging the curricula and in selecting the children suitable for the various types of schools. The number of pupils attending the various types of schools will ultimately be regulated by the laws of supply and demand. The training for industrial or trade occupations, if it is to be successful, must be given in special schools, such as preparatory trade schools, schools of arts and crafts, or technical institutes; and the instruction, whilst not neglecting the general education of the pupils, must include sound preliminary training in the theory and practice of the trades, whether of an artistic, scientific, or mechanical character.

There must be no attempt in such schools to supersede the training of the workroom, workshop, or factory; their aim should be to provide an all-round acquaintance, both theoretical and practical, with the particular trade or group of trades which the pupils will enter, and so to make up in part for the loss of those opportunities of learning formerly provided by

$$
\text { NO. } 2 \text { I62, VOL. 86] }
$$

the apprenticeship system in various industrial occupations.

A good beginning has already been made in this direction in London by the trade schools for girls, and at the London. County Council schools and the Borough and Woolwich Polytechnics; there are similar opportunities for boys at the L.C.C. Paddington and Poplar Schools of Engineering, the Shoreditch Technical Institute for woodwork, the Borough Polytechnic Institute for engineering and metal trades, the Stanley School, the L.C.C. Central School of Arts and Crafts, and at the National Bakery and Confectionary School at the Borough Polytechnic Institute; there are others which might also be mentioned. There are also schools of various kinds in many of the principal towns of the country, such as Leeds, Liverpool, Bradford, and Wigan. In nearly all the schools mentioned the work is a full-time course, but railway companies and large employers of labour in various parts of the country have afforded facilities for their young workmen to attend classes for short periods in the daytime, to enable them to improve themselves both by study and practice in the trades in, which they are engaged. Some problems in boy-labour in Government departments are also receiving attention, though much remains to be done.

Without considerable elasticity, no scheme of industrial training in schools and institutes can be thoroughly successful or completely satisfy the industrial and commercial needs of a practical nation such as ours; such training must be post-elementary; that is, must come, not under the regulations governing elementary schools, but under those governing technical schools and institutes, as otherwise there is a danger of limitations in various directions; it may be trammelled by religious questions, by large classes, by rigidity of syllabuses, and will probably suffer from lack of freedom in the choosing. of suitable teachers for the work. The type of teachers employed in such schools is indeed one of the most important factors of success, and such teachers must be chosen rather for their special trade and workroom experience than for their academic qualifications. The cooperation of employers and foremen on advisory committees will also form an iniportant feature in the work.

In conclusion, it should be remembered that trade prospers only with a nation which has an adequate supply of technically trained skilled workers. It is generally believed by those who have paid attention to the subject, and it is the opinion of those who can speak with authority, that the trades in which we hold our own are those in which apprenticeship or its equivalent is not yet dead. As the opportunities for apprenticeship in various trades are becoming fewer and fewer, something in the way of a substitute is necessary, and this can be supplied by wise modification and extension of our educational system in the direction of industrial training.

C. T. Millis.

\section{DAYLIGHT SAVING?}

$\mathrm{N}$ the face of it, the proposed Daylight Saving Bill is distinctly good. For a certain season in the year the clerks in the City of London will get one more hour to spare before the sun goes down. As a result of this they will have more time for the enjoyment of fresh air, more time for outdoor amusements, more time to learn rifle shooting, gain more health, become happier men, and enjoy other benefits. If this is really the case, then the clerks in the west of England, who have for years and years enjoyed 33 per cent. more evening sun than those in the eastern counties, ought to exhibit at least some trace of the benefits which accrue from an extra dose of 
daylight. Possibly the inhabitants of Cornwall are really more happy and bright, vigorous and enterprising, than the inhabitants of Kent; but is this really a fact?

Next, where does happiness come in if on a cold spring morning you have to get up one hour earlier? What will the wife and children say to the arrangement? Turning out too soon on frosty mornings, groping about at 4 a.m., to find a box of matches to light the fire, may give rise to domestic irritation, bronchial catarrhs, and other illnesses. Thousands upon thousands of workmen in the north of England, to be at work at 6 a.m., when it is really 5 a.m., will have to disturb their households at the time specified. At the commencement of April a man will get up in the dark, walk to his factory in the dark, and commence work by artificial light. Whatever light and fuel has been saved on the previous evening in the house or workshop will be spent in the dark hours of the early morning. For about six months, or 182 days, which I believe is the period over which the new-fangled time is to extend, men will frequently have to rise before the sun; nature will be asleep, but he must be awake and run counter to Divine intentions. As matters now stand during this period workmen get up on 127 days after sunrise. The new Bill will reduce the number of these occasions to 52 . He will have been robbed of his morning daylight, and have 75 extra days of morning darkness.

There is not so much daylight saving in the Bill as may popularly be supposed. It gives an hour in the evening, but cuts off an hour in the morning. Will a darkness creating Bill please the British workman?

When to give pleasant afternoons to the few who always go to work in daylight, the workmen in this country, in their trains and trams, and on their "bikes" or on their feet, take to blundering about in the morning dark, it suggests an increase in the number of accidents, more litigation, more illnesses, and more funerals. Doctors and lawyers will have more employment, and insurance companies may raise their rates.

Many medical men are supporting this proposed alteration, and have emphasised the benefits that may accrue from the greater amount of sunlight that people will enjoy if these changes are adopted. Obviously, of course, those requiring more sunlight can, if they will, get up earlier in the morning without any dislocation or changes in standard time. But to compel all workers to get up an hour earlier some months of the year may have effects upon the health quite other than seems to be supposed. Man is largely the creature of habit, and the habits acquired by long usage cannot be broken through suddenly without ill results. When early in April the time is suddenly altered, the result will be that for some days, possibly weeks, workers, clerks, and all others compelled willy-nilly to accommodate themselves to this incompletely considered scheme will find themselves at work, still half asleep, with serious results to their own efficiency, to their own health, and their employers' pockets.

In addition to all this, as I have before said, England, by destroying the time standard of the world, will have gone back on her bargain with other nations, and her steamship and other communications with other countries will have been disturbed.

The defenders of the Bill admit that it has its defects, but they do not point out how these are to be remedied.

To say that different parts of the United States keep different times, and that Cape Colony has found the adoption of the 3 oth meridian a boon, has nothing whatever to do with the question at issu. These and other countries have adopted a fixed time and adjusted their clocks to the Greenwich standard and not to a time that is altered at least twice a year. In these circumstances why references to the United States and Cape Colony have been brought forward I do not understand. The unthinking public might infer that because certain countries have altered their clocks there can be no great harm in altering ours. If this was seriously intended, these arguments are a reflection upon their authors, and indicate that certain reasons for the adoption of the Daylight Saving Bill rest upon curious foundations.

Some years ago, with the assistance of the Foreign, Colonial, and India Offices, I had occasion to inquire into the varieties of time kept by all accessible communities of the world. The only people I remember that have a shifty time are Mahomedans and savages, and it is now suggested that we should take a step downwards and join their ranks.

Astronomers and navigators are, however, to be left in peace. I imagine that those who desire to save daylight recognise that a movable time system might lead to shipwreck and to difficulties in the construction of nautical almanacs, and other astronomical work. If these departments are to be freed from the new arrangements, why should not the same freedom be given to meteorology and all other sciences in which it is necessary to have time observations comparable with those of other countries?

The simplest solution to the whole question would be to commence work one hour earlier in the morning and not confuse ourselves and others by altering the clock. In Japan thousands of schools open in the summer time at 7 a.m., Government offices open at eight and close at two; and what is done in Japan is done in other countries. Surely it is possible for business houses in this country to do something similar.

JoHN Milne.

\section{THE DESTRUCTION OF LOCUSTS. ${ }^{1}$}

A REPORT recently received from the South A African Central Locust Bureau bears testimony to the strenuous efforts which have been made during the last four years by the various Government entomologists and others in the systematic collection and tabulation of data regarding the more important phases in connection with the destruction of crops by migratory and other locusts. We congratulate the editor and his colleagues on the most excellent results which they have achieved, and the thanks of the country are also due to them for the valuable assistance which they have rendered to the agriculturists in Cape Colony and elsewhere by the successful methods which they have adopted in checking the ravages of these destructive insects.

In the introduction of the report we are informed that the South African Central Locust Bureau was formed in 1906 through the instrumentality of the Earl of Selborne, then his Majestv's High Commissioner in South Africa. His Excellency saw clearly that several colonies and territories under his supervision would benefit mutually if each were kept informed in regard to locust occurrences and to locust destruction, and measures in the territory of its neighbours, and that it was highly desirable in order that the pest might be intelligently combated, that the origin and movement of invading swarms be elucidated. The 1909 campaign cost the Government a

1 Fourth Annual Report of the Committee of Control of the South African Central Locust Bureau. Respectfully submitted by the committee to the several Governments supporting the Bureau. Edited by Chas, P. Lounsbury, Government Entomologist, Cape Town, Cape of Good Hope. Pp. 59+15 maps. (Cape Town: Cape Times, Ltd., Government Printers, т910.)

xo. 2 I62, VOL. 86] 